\title{
GERMINAÇÃO DE SEMENTES DE AZEDINHA (Oxalis hirsutissima), ESPÉCIE MEDICINAL DE MATO GROSSO, BRASIL ${ }^{1}$
}

\author{
Maria de Fátima B. COELHO*, Maria Cristina de F. ALBUQUERQUE*, \\ Jefferson Luis D. DOMBROSKI*
}

RESUMO - Sementes de azedinha (Oxalis hirsutissima Mart. \& Zuc.) apresentam um baixo percentual de germinação, dificultando a propagação dessa espécie medicinal, tão utilizada pelas populações tradicionais da região contra as inflamaçôes oculares. Sementes coletadas de uma população nativa $\mathrm{cm}$ Poconé, no Estado de Mato Grosso, foram submetidas a dois ensaios de quebra de dormência. No primeiro foram usados 12 tratamentos: pré-embebição em água por $24,36,48,69$ e 96 horas, imersão em acetona por 10 e 40 minutos, imersão em ácido cloridrico por 10 e 40 segundos, imersão em álcool etílico $96^{\circ}$ por 10 e 40 segundos, e sem pré-tratamento. No segundo ensaio foram usados 14 tratamentos: imersão em água quente $\left(70^{\circ} \mathrm{C}\right)$ por 20,40 , 60 e 300 segundos; em água muito quente $\left(85^{\circ} \mathrm{C}\right)$ por $20,40,120$ e 300 segundos, em água fervendo $\left(100^{\circ} \mathrm{C}\right)$ por $10,20,40,120$ e 300 segundos, e sem pré-tratamento. A imersão em ácido clorídrico por 40 segundos diferiu estatísticamente dos demais, e mesmo assim a porcentagem de germinação foi baixa (47\%). A imersão em água quente $\left(70{ }^{\circ} \mathrm{C}\right)$ por 300 segundos e em água muito quente $\left(85^{\circ} \mathrm{C}\right)$ por 40 segundos mostraram os melhores resultados, com 89 e $92 \%$ de germinação, respectivamente. A água fervendo $\left(100^{\circ} \mathrm{C}\right)$ por 300 segundos reduziu a percentagem de germinação a $4 \%$.

Palavras-chave: dormência, pré-germinaçào, planta medicinal.

\section{Seed Germination of Oxalis hirsutissima, Medicinal Plant of Mato Grosso, Brazil}

ABSTRACT - The germination of Oxalis hirsutissima Mart. \& Zuc. seeds is frequently low, making difficult the propagation of this important medicinal plant, widely used by local people for eye inflammations. Seeds of a wild population of the plant were collected in Pocone, Mato Grosso, Brazil, and tested in two different experiments to break dormancy. In the first experiment 12 treatments were used: imbibition in water for $24,36,48,69$, and 96 hours, immersion in acetone for 10 and 40 minutes, immersion in hydrochloric acid for 10 and 40 minutes, immersion in alcohol $96^{\circ}$ for 10 and 40 minutes, and no treatment. In the second experiment 14 treatments were used: immersion in warm water $\left(70^{\circ} \mathrm{C}\right)$ for $20,40,60$ and 300 seconds, in hot water $\left(85^{\circ} \mathrm{C}\right)$ for $20,40,120$ and 300 seconds, in boiling water $\left(100^{\circ} \mathrm{C}\right)$ for $10,20,40,120$ and 300 seconds, and no treatment. Immersion in hydrochloric acid for 40 seconds was statistically different from the others, although the germination percentual was still low (47\%). Immersion in warm water $\left(70^{\circ} \mathrm{C}\right)$ for 300 seconds and hot water $\left(85^{\circ} \mathrm{C}\right)$ for 40 seconds showed the best results, with $89 \%$ and $92 \%$ of germination, respectively. $100^{\circ} \mathrm{C}$ for 300 seconds reduced germination to $4 \%$,

Key-words: dormancy, pre-germination, medicinal plant.

\section{INTRODUÇÃO}

Os cerrados de Mato Grosso apresentam diversas espécies de plantas nativas que são utilizadas como medicinais pelas comunidades tradicionais. A azedinha (Oxalis hirsutissima Mart. \& Zuc.), pertencente a família Oxalidaceae, é subarbustiva, contem ácido oxálico e sua decocção é útil para combater anginas (Correa, 1926). O chá das flores

\footnotetext{
'Financiado pelo Conselho Nacional de Desenvolvimento Cientifico e Tecnológico-CNPq

*Universidade Federal de Mato Grosso, Dept ${ }^{\circ}$ de Fitotecnia e Fitossanidade-FAMEV, Av. Fernando Correa da Costa s/nº. CEP 78060-900 - Cuiabá/MT. Fax: 06561586 09. E-mail: mcfa@cgi.ufmt.br.
} 
e frutos é usado para problemas digestivos (Miranda, 1986), o sumo das folhas para o tratamento de inflamações oculares e o chá de raízes e folhas para desinterias e limpeza da pele por ocasião da gestação (Guarim Neto, 1987).

A espécie distribui-se em quase todo o Brasil (Correa, 1926). Em Mato Grosso ocorre em áreas de cerrado dos municípios de Cuiabá, Poconé, Barão de Melgaço e Santo Antônio do Leverger, que de acordo com a descrição fisionômica de Eiten (1994) são denominadas de "campo sujo" e "campo limpo".

Os frutos da azedinha são cápsulas ovóides, com cinco lóbulos, e a dispersão das sementes é autocórica. $\mathrm{O}$ peso médio de 100 sementes é $0,3 \mathrm{~g}$. A frutificação ocorre no final do período chuvoso (março a abril) e dispersão das sementes em abril e maio.

A germinação das sementes de azedinha é muito baixa em condições de viveiro, dificultando a sua propagação. A dormência em algumas espécies evoluiu como um mecanismo de sobrevivência à condições climáticas adversas, mas dificulta a germinação em trabalhos de propagação, sendo necessário estudar meios que permitam aumentar e acelerar a germinação, principalmente quando se pretende obter mudas (Popinigis, 1985). Como a dispersão de suas sementes ocorre no início do período seco, que é uma condição desfavorável a germinação no seu habitat, é possivel que esteja envolvido algum tipo de dormência. O presente trabalho visa estudar tratamentos pré-germinativos para superar a dormência das sementes de azedinha.

\section{MATERIAL E MÉTODOS}

Frutos e sementes de azedinha foram coletadas manualmente em várias plantas de uma população nativa no município de Poconé, estado de Mato Grosso - Brasil, durante a época de dispersão natural em abril de 1994, e acondicionados em saco de papel. Todas as sementes obtidas foram colocadas numa bandeja de plástico e ficaram durante quinze dias no ambiente da sala de recepção $\left(28^{\circ} \mathrm{C}\right)$ do Laboratório de Sementes da Faculdade de Agronomia e Medicina Veterinária da Universidade Federal de Mato Grosso, em Cuiabá - Mato Grosso.

Com estas sementes recémcoletadas e secas, foram realizados dois ensaios, com três repetições de 25 sementes, em delineamento inteiramente ao acaso. As sementes foram submetidas aos seguintes tratamentos no primeiro ensaio: préembebição em água destilada a $25^{\circ} \mathrm{C}$ por $24,36,48,69$ e 96 horas; imersão em acetona pura (P.A.) por 10 e 40 minutos; imersão em ácido clorídrico puro (P. A.) por 10 e 40 segundos e imersão em álcool etílico $96^{\circ}$ por 10 e 40 segundos. Nas sementes da testemunha nenhum tratamento foi aplicado. No segundo ensaio, as sementes foram submetidas a imersão em água em temperaturas e tempos variados: $70^{\circ} \mathrm{C}$ por $20,40,60$ e 300 segundos; $85^{\circ} \mathrm{C}$ por $20,40,120$ e 300 
segundos e, $100^{\circ} \mathrm{C}$ por $10,20,40,120$ e 300 segundos, sendo comparadas com as sementes sem nenhum tratamento.

O teste de germinação, após cada tratamento, foi realizado sobre papel filtro em caixas gerbox transparentes, colocadas em germinador a $25^{\circ} \mathrm{C}$, sendo as sementes avaliadas diariamente por um período de 14 dias, observando-se a porcentagem e velocidade de germinação. Considerou-se sementes germinadas após a emissão da raiz primária. Verificou-se também as porcentagens de sementes dormentes e mortas, conforme descrito nas Regras para Análise de Sementes (Brasil, 1992).

A velocidade de germinação foi determinada em número de dias médios por meio da fórmula : (n1t1 + $\mathrm{n} 2 \mathrm{t} 2+\mathrm{n} 3 \mathrm{t} 3+\ldots+\mathrm{nxtx}) / \mathrm{N}$, onde n é o número de sementes germinadas num intervalo consecutivo de tempo, $\underline{t}$ é tempo entre o início do teste e o final de um intervalo particular de medida, e $\underline{\mathrm{N}}$ é o número total de sementes germinadas (Hartmann \& Kester, 1975).

No primeiro ensaio, os dados originais foram transformados para raiz quadrada de $(x+0,5)$. No segundo ensaio, os dados originais de sementes germinadas foram transformados para arcoseno da raiz quadrada de $(\mathrm{x} / 100)$, de sementes dormentes e mortas para raiz quadrada de $(x+20)$ e de velocidade de germinação para logaritmo de $(x+10)$, antes da análise estatística, a fim de satisfazer as pressuposições da análise de variância, e as médias foram comparadas pelo teste de Tukey a $5 \%$ de probabilidade (Snedecor \& Cochran,1977).

\section{RESULTADOS E DISCUSSÃO}

No primeiro ensaio observou-se diferença significativa na germinação das sementes apenas entre os tratamentos imersão em água por 69 horas e imersão em ácido clorídrico por 40 segundos, sendo este último o que apresentou o melhor resultado (Tab. 1). Não verificou-se diferença significativa entre os tratamentos quanto a velocidade de germinação. Em geral observou-se um percentual elevado de sementes dormentes, evidenciando que os tratamentos efetuados não foram efetivos na eliminação da dormência.

No segundo ensaio notou-se maior efeito dos tratamentos sobre a germinação das sementes, comprovado pela baixa porcentagem de sementes dormentes, embora não tenha havido diferença significativa na velocidade de germinação (Tab. 2). Os tratamentos $70^{\circ} \mathrm{C}$ por 300 segundos e $85^{\circ} \mathrm{C}$ por 40 segundos, se destacaram dos demais. Popinigis (1985) conseguiu a superação da dormência das sementes impermeáveis de Amorpha fruticosa utilizando maior período de imersão em água a $85^{\circ} \mathrm{C}$ (300 segundos).

Observou-se diferença na porcentagem de sementes dormentes entre a testemunha e os demais tratamentos de imersão em água quente. Na temperatura de $100^{\circ} \mathrm{C}$ por 
Tabela 1. Porcentagem (\%) de sementes germinadas, dormentes, mortas e velocidade de germinação de sementes de Oxalis hirsutissima submetidas a diversos tratamentos prégerminativos.

\begin{tabular}{|c|c|c|c|c|}
\hline Tratamentos & $\begin{array}{c}\% \text { de sementes } \\
\text { germi nadas }(1)\end{array}$ & $\begin{array}{l}\% \text { de sementes } \\
\text { dormentes }(1)\end{array}$ & $\begin{array}{c}\% \text { de sementes } \\
\text { mortas }\end{array}$ & $\begin{array}{l}\text { Vel germinação } \\
\text { (dias médios) }\end{array}$ \\
\hline Testemunha & $25 a b$ & $67 a b$ & 8 & 6.7 \\
\hline Água $\left(25^{\circ} \mathrm{C}\right) 24 \mathrm{~h}$ & $30 \mathrm{ab}$ & $57 a b$ & 13 & 8.7 \\
\hline Água $\left(25^{\circ} \mathrm{C}\right) 36 \mathrm{~h}$ & $22 a b$ & $67 a b$ & 11 & 7.7 \\
\hline Água $\left(25^{\circ} \mathrm{C}\right) 48 \mathrm{~h}$ & $24 a b$ & $63 a b$ & 13 & 7.2 \\
\hline Água $\left(25^{\circ} \mathrm{C}\right) 69 \mathrm{~h}$ & $18 \mathrm{~b}$ & $69 \mathrm{ab}$ & 13 & 7.0 \\
\hline Água $\left(25^{\circ} \mathrm{C}\right) 96 \mathrm{~h}$ & $19 a b$ & $77 a$ & 4 & 7.8 \\
\hline Acetona $10 \mathrm{~min}$ & $41 \mathrm{ab}$ & $46 b$ & 13 & 6.9 \\
\hline Aœtona $40 \mathrm{~min}$ & $33 a b$ & $67 a b$ & 0 & 9.8 \\
\hline $\mathrm{HCl} 10 \mathrm{~s}$ & $27 a b$ & $67 a b$ & 6 & 14.9 \\
\hline $\mathrm{HCl} 40 \mathrm{~s}$ & $47 a$ & $49 a b$ & 4 & 10.4 \\
\hline Álcool etilico a $96^{\circ} 10 \mathrm{~s}$ & $29 a b$ & $67 a b$ & 4 & 14.4 \\
\hline Álcool etilico a $96^{\circ} 40 \mathrm{~s}$ & $21 a b$ & $70 a b$ & 9 & 10.2 \\
\hline CV $(\%)$ & 12.10 & 5.80 & 39.01 & 15.36 \\
\hline
\end{tabular}

(1) Médias seguidas pela mesma letra na coluna nâo diferem entre si, pelo teste de Tukey, ao nivel de $5 \%$ de probabilidade.

300 segundos ocorreu uma porcentagem elevada de sementes mortas.

\section{CONCLUSÕES}

Na superação da dormência das sementes de azedinha pode-se utilizar a imersão das sementes em água a $85^{\circ} \mathrm{C}$ por 40 segundos ou a $70^{\circ} \mathrm{C}$ por
300 segundos. A imersão em água a $100^{\circ} \mathrm{C}$ por 300 segundos prejudicou a germinação das sementes.

\section{Bibliografia citada}

Brasil. 1992. Regras para análise de sementes. Secretaria Nacional de Defesa Agropecuária, Ministério da Agricultura e Reforma Agrária, Brasilia. 365p. 
Tabela 2. Porcentagem (\%) de sementes germinadas, dormentes, mortas e velocidade de germinação de sementes de Oxalis hirsutissima submetidas a diversos tratamentos prégerminativos.

\begin{tabular}{|c|c|c|c|c|}
\hline Tratamentos & $\begin{array}{c}\% \text { de sementes } \\
\text { germinadas(1) }\end{array}$ & $\begin{array}{c}\text { \% de sementes } \\
\text { dormentes(1) }\end{array}$ & $\begin{array}{c}\% \text { de sementes } \\
\text { mortas }\end{array}$ & $\begin{array}{l}\text { Vel. germinação } \\
\text { (dias médios) }\end{array}$ \\
\hline Testemunha & $25 \mathrm{bc}$ & $67 a$ & $8 \mathrm{bc}$ & 6.7 \\
\hline $70^{\circ} \mathrm{C}$ por $20 \mathrm{~s}$ & $72 a b$ & $16 b$ & $12 \mathrm{bc}$ & 7.4 \\
\hline $70^{\circ} \mathrm{C}$ por $40 \mathrm{~s}$ & $81 a b$ & $6 b c$ & $13 \mathrm{bc}$ & 7.0 \\
\hline $70^{\circ} \mathrm{C}$ por $60 \mathrm{~s}$ & $70 a b$ & $13 \mathrm{bc}$ & $17 \mathrm{bc}$ & 8.4 \\
\hline $70^{\circ} \mathrm{C}$ por $300 \mathrm{~s}$ & $89 a$ & $5 b c$ & $6 \mathrm{bc}$ & 8.6 \\
\hline $70^{\circ} \mathrm{C}$ por $20 \mathrm{~s}$ & $82 a b$ & $14 \mathrm{bc}$ & $4 \mathrm{C}$ & 9.1 \\
\hline $70^{\circ} \mathrm{C}$ por $40 \mathrm{~s}$ & $92 a$ & $2 c$ & $6 b c$ & 7.7 \\
\hline $70^{\circ} \mathrm{C}$ por $120 \mathrm{~s}$ & $81 a b$ & $10 \mathrm{bc}$ & $9 b c$ & 6.7 \\
\hline $70^{\circ} \mathrm{C}$ por $300 \mathrm{~s}$ & $76 a b$ & $14 \mathrm{bc}$ & $10 \mathrm{bc}$ & 7.1 \\
\hline $100^{\circ} \mathrm{C}$ por $10 \mathrm{~s}$ & $66 a b$ & $0 \mathrm{c}$ & $34 a b c$ & 6.7 \\
\hline $100^{\circ} \mathrm{C}$ por $20 \mathrm{~s}$ & $83 a b$ & Oc & $17 \mathrm{bc}$ & 5.8 \\
\hline $100^{\circ} \mathrm{C}$ por $40 \mathrm{~s}$ & $58 a b c$ & $0 c$ & 42abc & 4.6 \\
\hline $100^{\circ} \mathrm{C}$ por $120 \mathrm{~s}$ & $36 a b c$ & Oc & $64 a b$ & 7.3 \\
\hline $100^{\circ} \mathrm{C}$ por $300 \mathrm{~s}$ & $4 \mathrm{C}$ & Oc & $96 a$ & 10.3 \\
\hline CV (\%) & 19.81 & 6.34 & 16.97 & 7.74 \\
\hline
\end{tabular}

(1) Médias seguidas pela mesma letra na coluna nâo diferem entre si, pelo teste de Tukey, ao nivel de $5 \%$ de probabilidade.

Correa, M.P. 1926. Dicionário das plantas úteis do Brasil e exóticas cultivadas. Vol.1. Imprensa Nacional, Rio de Janeiro. p. 212-220.

Eiten, G. 1994. Vegetação. In: Pinto, M.N. (coord.). Cerrado: Caracterização, Ocupação e Perspectivas. Editora UnB, Brasilia. p. 17-73.

Guarim Neto, G. 1987. Plantas utilizadas na medicina popular do Estado de Mato 
Grosso. Conselho Nacional de Desenvolvimento Cientifico e Tecnológico (CNPq), Brasília. 58p.

Hartmann, H.T.; Kester, D.E. 1975. Plant propagation - principles and practices. 3 ed., Prentice Hall, New Jersey. 662p.

Miranda, E.J. 1986. Plantas do pantanal utilizadas na medicina popular: Santo Antônio do Leverger; Barão de Melgaço e Poconé. Monografia. Curso de Especialização em "Biologia dos Ambientes Inundáveis - Pantanal MatoGrossense", Universidade Federal de Mato Grosso, Cuiabá, Mato Grosso. 36p.

Popinigis, F. 1985. Fisiologia da semente. 2 ed., Brasilia, s.ed. 289 p.

Snedecor, G.W.; Cochran, W.G. 1977. Metodos Estatisticos. 4 ed.. Compañia Editorial Continental, Mexico. 703 p. 